\title{
¿CONCEPCIÓN-LIBRO DE REGLAS O CÓNCEPCIÓN-ORQUESTA DE NORMAS?
}

\author{
Marisa Iglesias Vila \\ Universidad Pompeu Fabra
}

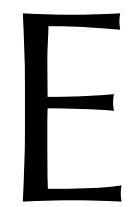

n la obra El imperio de la ley, una de las mejores contribuciones en español a los fundamentos de la legalidad, Francisco LAPORTA articula una aproximación al valor de la legalidad como rasgo identificativo del dominio de lo jurídico, que trata de explicar no solo por qué el Derecho está unido a este valor sino, también, por qué es un buen ideal para el Derecho.

Este ideal podría ser concretado de diversas formas; la suya consiste en defender, por una parte, que el imperio de la ley significa «imperio de las reglas» y, por otra parte, que ceñirnos a un gobierno de reglas es mejor si nos importan la autonomía personal, la previsibilidad y la voluntad democrática.

La claridad y profundidad de la trayectoria justificativa que LAPORTA despliega a lo largo del libro, así como su agudeza para identificar los nuevos desafíos que la filosofía del Derecho enfrenta, merecerían mucho más que este breve comentario. Me contentaré con apuntar algunas razones generales por las que creo que su construcción ética del imperio de la ley resultaría más convincente si desembocara en una concepciónorquesta de normas en vez de una concepción-libro de reglas.

Frente a los que entienden que hay una tensión básica entre autoridad y autonomía personal, LAPORTA defiende que el predominio de las reglas resulta necesario para hacer efectivo el valor de la autonomía personal. Su tesis es que predecir ex ante las consecuencias jurídicas de un cierto curso de acción es una condición necesaria para realizar este valor «en la mayor medida posible» (p. 34). El recorrido para justificar esta tesis empieza con un exhaustivo análisis del concepto de autonomía personal. LAPORTA lo presenta como un concepto gradual y complejo, que combina cuatro ingredientes: «La libertad negativa para realizar acciones, control racional de la satisfacción de preferencias de acuerdo a su jerarquía estratificada, proyección de las decisiones reflexivas en el tiempo y conformación de planes generales y abstractos interrelacionados» (pp. 33-34).

En el momento de conectar este concepto complejo con las estructuras normativas, sin embargo, el libro sostiene dos tesis separables. La primera es que dado que nos movemos en contextos de interacción mutua, la posibilidad de realizar nuestros proyectos autónomos a lo largo del tiempo requiere la existencia de normas sociales. Este juicio está muy bien fundamentado y su conclusión es difícil de objetar. Otra tesis distinta es que son las reglas el tipo de normas sociales necesarias para el desarrollo de 
la autonomía, ya que por su naturaleza aseguran la previsibilidad, y la previsibilidad es necesaria para que podamos ser agentes autónomos. Este juicio ya no me parece tan bien fundamentado. Para seguir el razonamiento de LAPORTA debemos primero aceptar que el imperio de las reglas es condición necesaria para la previsibilidad jurídica. Aunque no entraré en este punto, Isabel LIFANTE ha aportado ejemplos convincentes para mostrar que no hay una conexión ni necesaria ni suficiente entre la regulación por reglas y esta previsibilidad jurídica ${ }^{1}$.

Asimismo, la relación entre la previsibilidad y la autonomía se complica porque ambos conceptos son graduales y multidimensionales, lo que resiste una conexión simple entre ellos ${ }^{2}$. Para trazar un panorama claro de sus vínculos debemos preguntarnos, entre otros extremos, qué dimensión de la previsibilidad es necesaria para qué dimensión de la autonomía, y dentro de cada dimensión, y también combinándolas, qué grado de previsibilidad es necesario para qué grado de autonomía. Aunque el libro se adentra en esta discusión, no acaba de desentrañar la dinámica de relaciones dentro de esta red conceptual. LAPORTA se concentra en la idea de que la previsibilidad que otorgan las reglas es necesaria para realizar el valor de la autonomía personal «en la mayor medida posible». A pesar de ello, no siempre clarifica qué grado de previsibilidad resulta necesario. A veces nos habla de que la autonomía requiere un grado «mínimo» de previsibilidad (p. 142). En otras, en cambio, asume que es el alto grado de previsibilidad que las reglas en su opinión garantizan por naturaleza lo que hace posible una autonomía amplia. Dado que el concepto de autonomía combina varios ingredientes, mantener una cosa u otra marca una diferencia importante.

LAPORTA usa en varias ocasiones el ejemplo de los problemas de género para asumir que la previsibilidad puede convivir perfectamente con un entorno jurídico donde las mujeres carecen del nivel mínimo de autonomía, y dejan entonces de ser tratadas como agentes morales con capacidad de decisión para definir sus propios proyectos de vida a lo largo del tiempo. Siguiendo con este ejemplo, pensemos en la situación que se plantea en la película Yentl, cuya protagonista es una chica judía que quería estudiar el Talmud en un contexto donde una regla de la comunidad prohibía este tipo de estudio a las mujeres. Aquí podríamos preguntarnos de qué le servía la previsibilidad a Yentl para poder desarrollar su propio proyecto de vida dedicado al estudio. Para reivindicar su autonomía, necesitó primero la flexibilidad de su padre y tuvo que vulnerar luego las reglas de su comunidad. Si esas normas hubieran sido menos claras, más flexibles o menos predecibles ¿habría sido ella menos autónoma o, por el contrario, le hubiera sido más fácil reivindicar su autonomía? Para LAPORTA, un ejemplo como este sirve para reconocer que el imperio de la ley no es «suficiente» para respetar la autonomía personal. Pero este ejemplo también parece mostrar que no es «necesario».

Una ética de la legalidad anclada en el valor complejo de la autonomía personal debe poder armonizar dos variables: el rango de opciones que la ley deja abiertas y el grado en que estas opciones pueden ser conocidas de antemano. Mi opinión es que una previsibilidad alta solo podría ser condición necesaria para desarrollar la autonomía, vista ahora desde el plano individual, si un alto nivel de conocimiento previo de

\footnotetext{
1 Vid. LiFAnTE, 2013: 97-102.

2 Sobre el carácter graduable y complejo del concepto de previsibilidad, vid., de nuevo, LIFANTE, 2013.
} 
estas opciones contribuyera de algún modo a asegurar un rango razonable de opciones abiertas, quizá no en cada momento temporal, pero sí en el largo plazo de un proyecto de vida. En el ejemplo de Yentl, quizá cabría afirmar que una regulación con normas menos predecibles le hubiera facilitado un mayor rango inmediato de opciones abiertas, pero que solo una estructura normativa gobernada por reglas le permitiría desarrollar un proyecto de vida propio a largo plazo. Esta conclusión, sin embargo, no sería fácil de aceptar en el caso de Yentl. En comunidades cerradas y patriarcales como la suya, lo habitual sería que este tipo de reglas se mantuviera estable en el tiempo, con lo que su proyecto personal dedicado al estudio no podría prosperar. Si nos centramos en este ejemplo, aunque la posibilidad de desarrollar planes de vida requiere una estructura normativa que garantice un mínimo nivel de previsibilidad, nos acercamos más al valor multidimensional de la autonomía personal si el grado de previsibilidad no es tan alto como para impedir la flexibilidad normativa. Y esta combinación entre flexibilidad y una mínima previsibilidad la podemos obtener mucho mejor desde estructuras normativas que, al modo de una orquesta bien afinada, combinen reglas y principios que se apoyan y acomodan mutuamente ${ }^{3}$.

Esta posible debilidad de aproximarse a la legalidad desde la concepción-libro de reglas se resolvería, en la argumentación de LAPORTA, cuando abandonamos el plano individual de la autonomía para centrarnos en el plano de la autonomía política que redunda en la voluntad democrática. En sus términos, «Sería paradójico que concediéramos a la persona la capacidad de diseñar su propia vida y le regateáramos al mismo tiempo la participación en las normas que han de configurar el marco de ese diseño vital» (p. 146), «no pretendo apoyarme en el argumento —-seguramente artificioso- de que seamos nosotros los que nos impongamos la ley a nosotros mismos. Es algo mucho más limitado pero ineludible: que cualquiera que sea la autoridad encargada de elaborar la disposición jurídica en cuestión, tenga cada uno un derecho en su constitución y elección, y sea así tratado como un ser autónomo, y que ese derecho sea un derecho igual al de los demás, y sea así tratado como un igual» (p. 165).

Mi duda es, no obstante, si el concepto normativo de democracia, otra noción gradual y multidimensional [una vez hemos descartado, como LAPORTA hace, una visión estrictamente formal de democracia (p. 165)], puede entrar en tensión con un sistema de reglas que garantice un alto grado de previsibilidad. Pensemos en una de las objeciones democráticas a la Constitución que se mencionan en el capítulo diez del libro, «que una generación no tiene derecho a vincular a la generación siguiente ni a privar a sus individuos de su derecho pleno a participar» (p. 240). Esta objeción democrática

${ }^{3}$ Dejaré al margen otras normas que también podrían formar parte de esta orquesta. LAPORTA tiene una comprensión de los principios muy dependiente de su visión de las reglas como patrón ideal de normas jurídicas, lo que le conduce a percibirlos como pautas intratables, demasiado abstractas e imprecisas para limitar el decisionismo judicial (p. 124). Aunque no podré entrar en esta discusión, si percibimos los principios como normas diferentes a las reglas, con un funcionamiento propio, no tendremos dificultades en asumir que también hay casos fáciles de aplicación y ponderaciones fáciles entre principios. Es más, desde una visión de las reglas como generalizaciones atrincheradas, estas son el resultado de balances entre razones subyacentes, y su resistencia como reglas depende también de ponderaciones entre principios formales y sustantivos. Es la presencia de casos fáciles en la aplicación y balance entre todos estos principios lo que nos permite tener muchas de las reglas jurídicas que poseemos y confiar, al mismo tiempo, en que estas reglas no son arbitrarias. Vid., p. ej., ATIEnZA, 2006: cap. 4. 
podría dirigirse a la mayoría de normas constitucionales, tanto reglas como principios, pero en particular a las reglas con las que una generación ha pre-comprometido a las generaciones posteriores petrificando contenidos. ¿Podríamos utilizar un argumento democrático parecido contra una visión del imperio de la ley centrada en la previsibilidad?

Todos asumimos que la ley, como producto deliberado de la legislación, es un reflejo de la voluntad democrática cotidiana por su pedigrí y porque puede ser modificada con mucha mayor facilidad que una Constitución. Pero las diferencias entre la ley y la Constitución son también de grado, y dependen de cada ordenamiento jurídico. Dejando al margen las categorías que manejamos, una Constitución fácilmente reformable podría no estar muy lejos de una ley orgánica exigente. Si esto es así, una ley que, gracias a su alto grado de previsibilidad, consigue petrificar hoy la solución normativa de situaciones que se darán en el futuro cuando: a) su reforma puede ser ardua, y $b$ ) encapsula realidades y circunstancias complejas o que pueden variar con rapidez, arrastraría en algún grado la objeción democrática, incluso siento la ley el producto de la representación democrática. En estas condiciones, cuando el ideal del imperio de la ley persigue, además de regular ex ante, la estabilidad de las leyes en el tiempo, la objeción democrática puede tornarse más fuerte. Por esta razón, al menos en contextos regulativos donde las circunstancias relevantes son múltiples y variables, el argumento democrático puede también aconsejar que regulemos a través de principios, estándares o reglas con conceptos valorativos, que se adaptan mejor a las necesidades del presente ${ }^{4}$.

Podemos responder a esta objeción del mismo modo que hace LAPORTA respecto a la Constitución, afirmando que esta línea crítica conduce la objeción democrática demasiado lejos. Así, indica, «para respetar el derecho a participar de cada uno en los términos estrictos de la objeción sería necesario reabrir el debate decisorio. Y como todos los días habría algún ciudadano en esta situación, eso sería tanto como mantener permanentemente abierto ese proceso. [...] Al menos alguna decisión anterior ha de tener normalmente un periodo de vida en que regule las conductas de los ciudadanos sin que pueda ser puesta en cuestión por otra mayoría. [...] Las normas por las que se ordena la sociedad han de tener otras propiedades además de la de ser democráticas en origen: por ejemplo, deben disfrutar de una cierta estabilidad, ser públicas, no ser retroactivas, etc. [...] La objeción democrática va demasiado lejos. Y debe ser acompañada de una serie de medidas que "atrincheren" sus decisiones, incluso frente a sí misma» (pp. 241-242). Aunque estas apreciaciones sean acertadas, lo que me interesa destacar es que esta discusión muestra que la previsibilidad y la participación democracia no siempre se apoyan mutuamente. Por este motivo, de modo similar a lo que sucede con el valor de la autonomía personal, el argumento democrático no dirige necesariamente a una concepción del imperio de la ley como predominio exclusivo de las reglas.

Una forma de disminuir esta potencial aspereza entre la visión formalista del imperio de la ley y el argumento de la participación democrática es considerar que las reglas,

${ }^{4}$ Sobre los diferentes tipos de normas que se requieren en función de las diversas circunstancias regulativas vid., en general, HART, 1961: cap. 7; ATIENZA y RUIZ MANERO, 1996. 
como significados de disposiciones normativas, se van amoldando a las circunstancias del presente a través de la interpretación. Aunque LAPORTA no vincula democracia y modos de interpretación, su visión del significado podría servir a este propósito. En su opinión, ni el autor del texto ni el juez en el caso particular determinan el significado de las disposiciones normativas. El texto adquiere una vida independiente cuyo significado está ligado a las convenciones lingüísticas de la comunidad de hablantes competentes. Además de los problemas que LAPORTA plantea sobre la identificación del autor de las leyes, centrarse en la intención original para asignar significado irá resultando cada vez más problemático desde la lógica democrática a medida que se vayan distanciando en el tiempo la creación y la aplicación normativa. Atender a las convenciones lingüísticas en cada momento temporal de aplicación nos permite tener reglas actualizadas a pesar de que las disposiciones normativas sigan inalteradas, es decir, a pesar de que el legislador no haya decidido introducir un nuevo texto dotado de autoridad. Pero si las disposiciones normativas son estables y lo que puede variar es su significado, las reglas, suavizamos la objeción democrática al coste de renunciar a un alto grado de previsibilidad. Pensemos en el caso Pinochet, por ejemplo. La Audiencia Nacional defendió en 1998 la competencia de los tribunales españoles para juzgar a Pinochet alegando, entre otros extremos, que la convención semántica sobre el concepto de genocidio había cambiado. Para la posición de la Fiscalía del Estado, tener en cuenta este cambio en las convenciones ponía en peligro la seguridad jurídica. Un problema parecido lo hemos encontrado durante mucho tiempo con los conceptos de cónyuge o de familia. A falta de cambios legislativos en esta materia, adaptar las disposiciones normativas a las nuevas convenciones lingüísticas [interpretación evolutiva que LAPORTA parece ver con buenos ojos (p. 183)] resultaba más democrático, pero al coste de hacer menos previsible la regulación jurídica de las relaciones de pareja. Y todo ello en el supuesto de que consideremos que es posible identificar en cada momento temporal una única convención lingüística. Como se destaca a menudo, la trascendencia práctica de la aplicación del Derecho para la vida de los ciudadanos facilita que haya convenciones en conflicto o que las convenciones sean controvertidas, porque el lenguaje refleja nuestro modo de vida y, en definitiva, nuestros valores, necesidades e intereses ${ }^{5}$. Determinar cuál de ellas es la relevante, o en qué momento una asignación de significado está asentada lo suficiente para contar como «la convención semántica» de la comunidad competente de hablantes, requiere decisiones, con lo que la previsibilidad queda aquí todavía más lejos. Con independencia ahora de muchos otros problemas filosóficos, la variabilidad y el carácter controvertible de las convenciones lingüísticas genera dificultades a una ética formalista de la legalidad que pretenda vincular una concepción-libro de reglas con el convencionalismo semántico, confiando en que ello garantizará regulaciones ex ante y predecibles. Confiar (ingenuamente) en que los textos jurídicos tienen un autor y que su intención inicial determina su significado, es decir, que podemos conocer las reglas desde su origen, parece más fiel a este ideal del imperio de la ley pero, de nuevo, menos convincente desde el argumento democrático.

En conclusión, mis dudas con esta brillante defensa ética de la concepción-libro de reglas es que ni su fundamento en el valor de la autonomía personal ni su apoyo en los

5 Vid., p. ej., AARNIO, 1997: 101-102. 
argumentos democráticos parecen dirigir a esta visión del imperio de la ley. Dirigen, más bien, a una noción menos formalista de la legalidad, menos previsible pero más flexible, que aboga por estructuras normativas híbridas. LAPORTA prefiere desplazar esta orquesta combinada de reglas y principios a los casos difíciles y al Derecho implícito, pero esta limitación tiene un aire de petición de principio porque es interna a su propia posición en torno al dominio de lo jurídico.

A mi juicio, esta orquesta afinada de normas es lo que da sentido al constitucionalismo democrático, y es lo que debería orientar la globalización jurídica si pretendemos asentar bases sólidas para ubicar el lugar del Derecho dentro de estructuras equitativas de cooperación social que trascienden el estrecho marco nacional. HART decía que en sociedades complejas el Derecho no puede ser otra cosa que una unión de reglas primarias y secundarias. Mi sospecha es que en sociedades constitucionalizadas y globalizadas el Derecho no puede ni debe ser otra cosa que una unión de reglas y principios.

\section{BIBLIOGRAFÍA}

Aarnio, A., 1997: Reason and Authority. A Treatise on the Dynamic Paradigm of Legal Dogmatics, Dartmouth: Ashgate.

AtienZA, M., 2006: El Derecho como argumentación, Barcelona: Ariel.

AtienZA, M., y Ruiz MAnero, J., 1996: Las piezas del Derecho. Teoría de los enunciados jurídicos, Barcelona: Ariel.

HART, H., 1961: The Concept of Law, Oxford: Clarendon Press.

LAPORTA, F., 2007: El imperio de la ley. Una visión actual, Madrid: Trotta.

LIFANTE, I., 2013: «Seguridad jurídica y previsibilidad», Doxa, 36, 85-105. 